\section{EPISTEMOLOGIA DA EDUCAÇÃO FÍSICA BRASILEIRA: (RE)DESCRIÇÕES DA ATIVIDADE EPISTEMOLÓGICA NO SÉCULO XXI}

\author{
EPISTEMOLOGY OF BRAZILIAN PHYSICAL EDUCATION: (RE) \\ DESCRIPTIONS OF EPISTEMOLOGICAL ACTIVITY IN THE $21^{\text {ST }}$ \\ CENTURY
}

EPISTEMOLOGÍA DE LA EDUCACIÓN FÍSICA BRASILEÑA: (RE)

DESCRIPCIONES DE LA ACTIVIDAD EPISTEMOLÓGICA EN EL SIGLO $X X I$

\section{Gabriel Carvalho Bungenstab*}

\begin{abstract}
Resumo: O objetivo deste texto é mapear e analisar, em termos de artigos científicos, a produção desenvolvida pelo campo da Educação Física brasileira no que diz respeito às (re)configurações do debate epistemológico da área. A partir do debate travado no fim do século XX que polarizou as teorias entre a "vertente científica" e a "vertente pedagógica", foi realizada uma revisão sistemática de literatura nos principais periódicos da área a fim de analisar aqueles artigos que atualmente se interessam em discutir a relação entre a Educação Física e a ciência. Indica, por fim, que o debate epistemológico atual é acalorado no que tange aos giros epistemológicos, mas também vê emergir uma atividade epistemológica que visa defender a pluralidade de teorias e ideias na área.
\end{abstract}

Keywords: Physical

Education. Epistemology. Scientific publication indicators. Journal article.

Palabras clave: Educación Física. Epistemología. Indicadores de Producción científica. Artículo de revista.
Abstract: This text maps and analyzes, in terms of scientific articles, the work developed by the field of Brazilian Physical Education regarding the (re) configurations of the area's epistemological debate. Based on the debate at the end of the 20th century that polarized theories between the 'scientific strand' and the 'pedagogical strand', a bibliographic survey was carried out in the field's main journals in order to analyze those articles that are currently focused on the relationship between Physical Education and Science. Finally, it indicates that the current epistemological debate is heated in terms of epistemological turns, but it also sees an emerging epistemological activity advocating the plurality of theories and ideas in the area.

Resumen: El objetivo de este texto es mapear y analizar, en términos de artículos científicos, la producción desarrollada por el campo de la Educación Física brasileña en lo que se refiere a las (re)configuraciones del debate epistemológico del área. Basado en el debate desarrollado a fines del siglo XX, que polarizó las teorías entre la "vertiente científica" y la "vertiente pedagógica", se realizó una revisión sistemática de literatura en las principales revistas y periódicos del área para analizar aquellos artículos que actualmente se interesan en discutir la relación entre la Educación Física y la ciencia. Finalmente, indica que el debate epistemológico actual es acalorado en lo que atañe a los aspectos epistemológicos, pero también ve emerger una actividad epistemológica que tiene como objetivo defender la pluralidad de teorías e ideas en el área..
*Universidade Estadual de Goiás. Goiânia, GO, Brasil. E-mail: gabrielcarv@msn.com

Recebido em: 17-02-2020 Aprovado em: 01-04-2020 Publicado em: 26-04-2020 (c) (i) (2) Licence 


\section{INTRODUÇÃO}

A discussão sobre o estatuto epistemológico ${ }^{1}$ do campo da Educação Física (EF) abrange diversas concepções e perspectivas que tem no seu cerne a discussão sobre a racionalidade. O debate epistemológico da EF no Brasil nas décadas de 1980 e 1990 concentrou-se na crise de identidade sofrida pela área e na busca pela sua legitimidade científica. Como ressalta Fensterseifer (2000, p. 35), a racionalidade universalista da modernidade influenciou o campo da EF na medida em que seus discursos se concentraram em torno de uma possível unidade epistemológica que objetivaria produzir e legitimar conhecimentos.

Com a possibilidade de avanço rumo ao seu estatuto científico, no fim do século $X X$, houve na área uma preocupação com a mudança das questões instrumentais, técnicas e metodológicas, numa tentativa de superar a pesquisa que era realizada com teorias e métodos já desenvolvidos em outras áreas científicas. Desta forma, segundo Lima (1999), era necessário definir questões epistemológicas próprias e, a partir deste momento, instalou-se uma crise de identidade que fez emergir diversos questionamentos sobre o assunto: a EF é uma ciência? A EF tem potencial e condições para ser uma ciência?

Para Lima (1999), estas perguntas elucidam um pouco das problemáticas levantadas pela intelectualidade da EF brasileira na época, divididas em duas vertentes: a) a vertente científica (na qual o foco principal foi à constituição de uma nova ciência, independente dos contornos que a EF iria revestir, recebendo um tratamento secundário) e; b) a vertente pedagógica (a EF como uma prática pedagógica e social, como foco central das suas preocupações). Na vertente científica ${ }^{2}$, temos: a Ciência da Motricidade Humana; a Ciência do Movimento Humano; a Cinesiologia; e as Ciências do Esporte. Já na vertente pedagógica ${ }^{3}$, temos: "a cultura corporal de movimento"; "a Educação Física como ciência da prática"; a "Educação Física como a arte da mediação"; e a "teoria da Educação Física como um campo dinâmico de pesquisa e reflexão".

Dando sequência ao debate realizado nos anos de 1990, a Revista Brasileira de Ciências do Esporte (RBCE) organizou, no ano 2000, um dossiê sobre o tema "Epistemologia e Educação Física". Esse dossiê contou com artigos de Valter Bracht, Go Tani, Homero Luis de Alves Lima, Paulo Fensterseifer, Eliane Pardo e Luis Carlos Rigo. Em síntese, os textos publicados neste dossiê avançaram no argumento de olhar a EF como uma área acadêmica que produziria e aplicaria conhecimento. Fensterseifer (2000), por exemplo, defendeu a ideia de que não fazia mais sentido procurar pela "verdadeira" EF. Para ele, seria mais profícuo identificar os diferentes discursos e as disputas que engendram o debate argumentativo do campo.

\footnotetext{
1 Para Gomes (2009) a epistemologia se configura como o estudo metódico e reflexivo do conhecimento, de sua natureza, de seu funcionamento e da validação de seus produtos intelectuais. Já a gnosiologia, refere-se à capacidade humana de conhecimento, não sendo, portanto, relacionada exclusivamente a um conhecimento científico.

2 Algumas questões são consenso entre os representantes desta vertente. A principal delas, segundo Lima (1999), é em relação à necessidade de conferir cientificidade à EF, reconhecendo, sobretudo, que a crise de identidade da área era uma crise epistemológica.

3 Lima (1999) diz que, no que tange aos representantes desta vertente, a EF esteve no centro das atenções, com foco na prática pedagógica e social sendo o ponto de partida e o ponto de chegada das problematizações, reflexões e questionamentos dos representantes.
} 
Nesta perspectiva, segundo Almeida, Bracht e Vaz (2012) houve, a partir do século XXI, uma polarização entre: a) os autores que defendem o giro linguístico; b) os autores que defendem o resgate do giro ontológico realista. Nesse bojo, uma das discussões que está sendo feita se refere à pertinência de duas classificações epistemológicas: a primeira, considerando a produção do conhecimento organizada em três matrizes teóricas (empírico-analítica; fenomenológico-hermenêutica e críticodialética) e a segunda, considerando a aposição entre modernos ${ }^{4}$ e pós-modernos ${ }^{5}$ na produção do conhecimento da área. Além disso, os autores criticam uma possível (des)qualificação da dialética materialista e histórica em relação às novas perspectivas contemporâneas, bem como, os rótulos que estas matrizes teóricas sofrem diante da primeira classificação.

Nesse bojo, vale a pena perguntar: o argumento de que não é mais válido buscar pela "verdadeira" EF, bem como os critérios de discussão/classificação epistemológicas emprestados de outras áreas (majoritariamente do campo da Filosofia da Educação) satisfazem à especificidade da EF? Parece que não há consensualidade no campo na medida em que se notam outros argumentos, desenvolvidos desde a década de 1990, e que também demarcam o estatuto científico da EF internacional e brasileira.

A obra de Manuel Sérgio (1991, 1994), por exemplo, teve um grande alcance no Brasil. Em síntese, Sérgio (1991) defendeu a existência de uma nova ciência (básica) do homem dentro da EF: a Ciência da Motricidade Humana. ${ }^{6}$ Seu objeto de estudo seria a análise do homem em movimento, abrangendo todas as condutas e situações motoras possíveis dentro da motricidade humana utilizando, para tal, uma fusão de diferentes métodos (histórico, biológico, fenomenológico, antropológico e psicológico), denominado por ele de método integrativo.

Kokubun (1995), se inserindo neste debate, acreditava que a tentativa de conferir um caráter filosófico-científico à EF estava permeada de vícios. Nesse sentido, discordava da ideia de sustentação da EF como uma ciência básica, fazendo ressalvas sobre as relações estabelecidas entre os pesquisadores da EF com outros campos do conhecimento, acreditando que tal condição contribuiria para a acentuação da fragmentação do saber. Para ele, seria necessária a formação de pesquisadores mais generalistas, capazes de utilizar diferentes instrumentos e teorias diante da prática profissional da EF, de forma aplicada. Mais recentemente, Souza (2019a) tem recuperado a ideia de que o movimento humano constitui o objeto e a organização da atividade científica do campo da EF. Para tal, sustenta um programa de uma EF reflexiva na tentativa de propor modelos de ação que satisfaçam as especificidades da profissão e deem base para uma ciência aplicada do movimento humano.

\footnotetext{
4 Para Peters (2000) os termos "moderno" e "modernidade" possuem caráter histórico e filosófico, referindo-se a um período de ruptura autoconsciente com o período anterior (clássico, medieval), em prol da ênfase no novo e na ideia de progresso. Esse movimento baseou-se na crença do avanço do conhecimento, por meio do método científico experimental, bem como na ênfase dada ao individualismo, à racionalidade e ao monopólio da ciência e do mundo das ideias filosóficas (como o marxismo, o positivismo e o freudismo).

5 A "pós-modernidade" ou "pós-moderno", segundo Peters (2000), representam uma mudança radical nos sistemas de valores e práticas do período moderno e, em seu sentido histórico e filosófico, criticam as explicações do mundo a partir dos metarrelatos, escapando a qualquer tentativa de uma definição teórica única.

6 Para Sérgio (1994), a Educação Motora (em substituição a EF) seria o "ramo pedagógico" da Ciência da Motricidade Humana. Esta Ciência, por sua vez, estaria radicada no paradigma emergente (com bases na fenomenologia e na hermenêutica).
} 
No desenrolar deste debate - ainda atual — diversos textos foram publicados com o intuito de fomentar a discussão sobre epistemologia na $E F$, muitas divergências foram levantadas e alguns avanços podem ser considerados, porém, até o momento nenhum consenso parece ter sido estabelecido. Diante do que foi dito, vale a pena perguntar: Qual é a configuração do debate epistemológico da EF na atualidade em termos de autores, número de artigos publicados e concepções teóricas? Parto da hipótese de que o atual debate não mais se preocupa em discutir, no âmbito estrutural, as diferentes concepções de ciência e de verdade; ao contrário, se direciona na tentativa de compreender, analisar e refletir quais são os limites e possibilidades que os mais diversos autores trazem para a EF.

Nesse sentido, interessa menos saber quais são as filiações teóricas dos diversos autores e mais em diagnosticar quais limites e possibilidades de suas teorias diante do conhecimento produzido pela EF. O objetivo deste texto é apresentar e analisar, em termos de artigos científicos, a produção desenvolvida pelo campo da EF no que diz respeito ao debate epistemológico da área.

Para tal, este artigo está organizado em três partes. Na primeira, descrevo o percurso metodológico pautado na revisão sistemática de literatura. A seguir, desenvolvo uma análise sobre o atual debate epistemológico do campo na tentativa de compreender, a partir de um mapeamento nos principais periódicos da área, como vem se configurando o debate sobre epistemologia da EF. Por fim, na conclusão, procuro estabelecer diálogos e consequências daquilo que foi discutido nas partes anteriores.

\section{METODOLOGIA}

O intuito foi o de realizar uma revisão sistemática de literatura, em termos de artigos científicos, com a intenção de compreender o desdobramento do debate epistemológico na área da EF no século XXI. A opção por este recorte temporal se justifica, pois, segundo Almeida, Bracht e Vaz (2012), é a partir do início do século XXI que a produção da EF brasileira sobre epistemologia passa a colocar em dúvida as classificações epistemológicas oriundas da produção científica da área, denunciando, sobretudo, seu caráter reducionista e simplório. A revisão sistemática de literatura é uma etapa fundamental em toda e qualquer pesquisa, já que possibilita reflexões sobre os limites, os problemas e as abordagens do conhecimento a ser pesquisado.

Soni e Kodali (2011) sugerem alguns passos na execução de uma revisão sistemática de literatura. Esses passos não procuram engessar o processo da pesquisa, mas sim definir critérios transparentes e consistentes que auxiliem na resolução dos problemas propostos pelo pesquisador. Em relação à produção de pesquisa em EF, o trabalho realizado por Gomes e Caminha (2014) é sintomático, sobretudo porque sugere alternativas para a realização da revisão sistemática de literatura no campo da EF.

Nesse sentido, elenco os passos seguidos nesta pesquisa e que, também, podem servir de base para pesquisas futuras. Os 11 passos são: 1) justificar a necessidade de se fazer a revisão; 2) definir o problema de pesquisa; 3) definição 
da estratégia de pesquisa; 4) definição do percurso metodológico da revisão; 5) definição dos critérios de inclusão e exclusão; 6) mapeamento da existência de possíveis revisões anteriores; 7) seleção dos trabalhos; 8) análise dos trabalhos e; 9) resultados das análises dos trabalhos; 10) suprir lacunas deixadas por revisões anteriores; 11) indicar agendas de trabalhos futuros.

$\mathrm{Na}$ esteira de Bungenstab (2018, p. 781), realizei um mapeamento dos principais periódicos da área da EF brasileira, a partir da classificação (quadriênio 2013-2016) "Qualis" da Coordenação de Aperfeiçoamento de Pessoal de Nível Superior (CAPES). Com o mapeamento, identificou-se os periódicos com as melhores avaliações, a saber: nenhuma revista avaliada como A1; a revista Movimento, avaliada como A2; a revista Motricidade, revista Motriz, RBCE, Revista Brasileira de Educação Física e Esporte (RBEFE) e Revista de Educação Física da UEM, avaliadas como B1 e as revistas Licere, Motrivivência, Pensar a Prática e Revista Brasileira de Atividade Física e Saúde, avaliados como B2. Diante disso, foram utilizados três (03) critérios de seleção e escolha das revistas a serem pesquisadas: o primeiro, revistas brasileiras da área da EF que publicam em língua portuguesa; o segundo, revistas com estratos "Qualis - CAPES" diferentes, tendo pelo menos uma revista de cada estrato, e o terceiro: revistas que desenvolvam o diálogo com o debate epistemológico da área (BUNGENSTAB, 2018).

Foram selecionados seis periódicos: as revistas Movimento, Motriz, RBCE, RBEFE, Motrivivência e Pensar a Prática. Em relação à pesquisa, inseri no campo de busca de cada revista a palavra-chave "epistemologia" e mapiei os artigos que fizeram referência ao termo no título, no resumo e/ou nas palavras-chave. Desta forma, os artigos que apresentaram o termo e estavam dentro do recorte temporal, foram préselecionados para a pesquisa. Após inserir a palavra-chave "epistemologia" na caixa de busca das páginas das respectivas revistas, foram encontrados 46 artigos na revista Movimento; 42 artigos na revista Motriz; 14 artigos na RBCE; 15 artigos na RBEFE; 11 artigos na Motrivivência e 33 artigos na revista Pensar à Prática.

Contudo, um olhar mais atento oportunizou verificar dois critérios de exclusão de textos que não tratavam especificamente sobre o tema "epistemologia": 1) em vários artigos, o termo apareceu vinculado à biografia dos autores e não, necessariamente, no seu corpo do texto e; 2) diversos textos utilizaram o termo de maneira coadjuvante para tratar de outros assuntos importantes ao campo, como lazer, formação docente e esporte.

\subsection{O DEBATE EPISTEMOLÓGICO NA EDUCAÇÃO FÍSICA: ANÁLISE DA PRODUÇÃO CIENTÍFICA DO SÉCULO XXI}

Neste tópico, mapearei a produção científica desenvolvida em EF sobre epistemologia no século XXI com o objetivo de analisar o debate da área. O gráfico 1 representa o número de artigos publicados em cada período durante os anos de

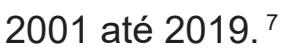

7 No fim de 2019, a revista Movimento publicou um dossiê discutindo a presença da "pedagogia crítica" da EF. Entendo que os textos publicados são de grande valia, contudo, acredito que se os inserisse aqui estaria correndo o risco de fugir do objetivo e extrapolar o limite máximo de páginas permitido pela revista. Desse modo, estes textos (nove artigos) não foram inseridos nas análises. 
Gráfico 1 - Frequência de artigos que contém a presença do termo "epistemologia" em cada periódico a partir do século XXI (2001-2019)

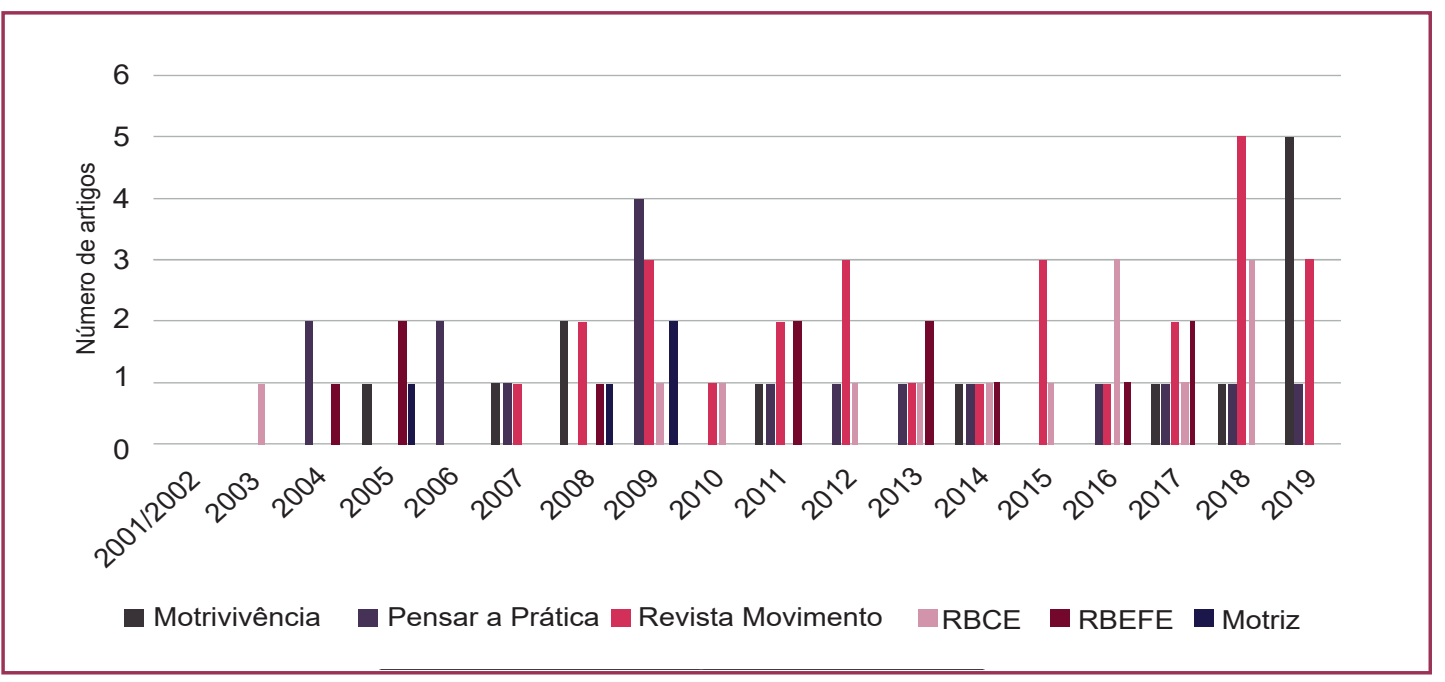

Fonte: elaboração do autor.

A partir deste primeiro mapeamento, o que se pode constatar sobre o atual debate epistemológico da área da $E F$, em termos de quantidade? No século XXI a revista Motrivivência publicou um total de 676 artigos, desses apenas nove apresentaram o termo "epistemologia". Tais artigos representam apenas 1,3\% do total de artigos. Já a revista Pensar a Prática publicou 830 artigos neste século e apenas $2 \%$ tratam da temática aqui estudada. A revista Movimento ${ }^{8}$, por sua vez, publicou 1000 trabalhos, sendo $2,8 \%$ contendo o termo "epistemologia". A RBCE publicou 919 artigos, destes, 1,5\% referem-se ao debate epistemológico. Por fim, a revista Motriz obteve um total de 1050 textos publicados sendo que $0,3 \%$ sobre o termo "epistemologia". Analisarei, em seguida, os artigos que tratam exclusivamente sobre o debate da EF e sua relação com a ciência. Para isso, elaborei o quadro 1 que apresenta a relação dos 25 artigos que tratam sobre o debate epistemológico da EF.

Quadro 1 - Ano, revistas e autores que discutiram "epistemologia" no século XXI.

\begin{tabular}{|c|c|c|c|}
\hline Ano & Revistas & Autores & Total \\
\hline 2003 & RBCE & Da Costa e Duarte & 1 \\
\hline 2005 & RBEFE & Betti & 1 \\
\hline \multirow{2}{*}{2009} & Movimento & \multirow{2}{*}{ Fensterseifer } & \multirow{2}{*}{2} \\
\hline & RBCE & & \\
\hline \multirow[b]{2}{*}{2010} & Movimento & Almeida e Vaz & \multirow{2}{*}{2} \\
\hline & RBCE & Velozo & \\
\hline \multirow{3}{*}{2011} & Motrivivência & Motta de Souza & \multirow{3}{*}{3} \\
\hline & Movimento & Seron et al. & \\
\hline & Pensar a Prática & Rezer, Nascimento e Fensterseifer & \\
\hline \multirow{2}{*}{2012} & Movimento & Almeida, Bracht e Vaz & \multirow{2}{*}{2} \\
\hline & RBCE & Rezer, Nascimento, Fensterseifer e Graça & \\
\hline
\end{tabular}

Continua na próxima página...

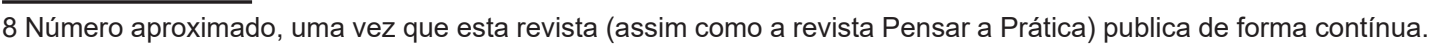


Continuação do quadro 1.

\begin{tabular}{|c|c|c|c|}
\hline \multirow{2}{*}{2013} & Movimento & Ghidetti & \multirow{2}{*}{2} \\
\hline & Pensar a Prática & Ghidetti, Almeida e Bracht & \\
\hline \multirow{2}{*}{2014} & Movimento & Da Nóbrega & \multirow{2}{*}{2} \\
\hline & RBCE & Rezer & \\
\hline 2015 & Movimento & Almeida, Bracht e Vaz & 1 \\
\hline \multirow{4}{*}{2018} & Movimento & Bortoluzzi et al. & \multirow{4}{*}{4} \\
\hline & Movimento & Bungenstab & \\
\hline & Movimento & Souza Silva, Andrieu e Nóbrega & \\
\hline & RBCE & Da Costa e Almeida & \\
\hline \multirow{4}{*}{2019} & Motrivivência & Bungenstab & \multirow{4}{*}{5} \\
\hline & Movimento & Gomes et al. & \\
\hline & Movimento & Souza & \\
\hline & Movimento & $\begin{array}{c}\text { Pires, Barbosa-Rinaldi e Souza } \\
\text { Vaz }\end{array}$ & \\
\hline Total & - & - & 25 \\
\hline
\end{tabular}

Fonte: elaboração do autor

Dentre os autores que mais publicaram sobre o debate epistemológico da EF brasileira na atualidade, identifiquei Felipe Quintão de Almeida com cinco publicações e Paulo Evaldo Fensterseifer, com quatro publicações. Além disso, pude constatar a partir destes dados que, dos autores que debateram nas décadas de 1980 e 1990, Mauro Betti, Valter Bracht e Paulo Fensterseifer continuaram interessados na discussão epistemológica da área depois dos anos 2000.

Nessa direção, identifiquei que os autores mais citados e referenciados dentre os 25 artigos analisados são: Valter Bracht, Mauro Betti, Sílvio Sanchéz Gamboa e Hugo Lovisolo. Com isso, me parece que a ideia destes autores "sobreviveram", pelo menos nas revistas analisadas, ao debate epistemológico em relação à crise de identidade sofrida pela área e a busca pelo seu estatuto científico. Visto isso, vale perguntar: quais contornos este debate assumiu a partir dos anos 2000?

\subsection{EDUCAÇÃO FÍSICA E CIÊNCIA: DE 2001 ATÉ 2010}

Na primeira década do século XXI, Betti (2005), Fensterseifer (2009), Velozo (2010), Almeida e Vaz (2010) foram alguns dos autores, dentre os pesquisados, que publicaram sobre o debate epistemológico dá área. Betti (2005) e Velozo (2010) se preocuparam em realizar leituras com o objetivo de contribuir com o debate acalorado ocorrido, no Brasil, nas décadas de 1980 e 1990.

Se ancorando na Filosofia da Ciência, Betti (2005) buscou eliminar as fragmentações e dualidades causadas pelo debate estanque que polarizou as matrizes científicas e pedagógicas. Defendendo que as visões científicas e a delimitação de objetos específicos para a EF não dão conta de compreender a realidade da área pelo fato de serem, sempre, reducionistas, Betti $(2005$, p. 193) propõe que a prática pedagógica EF seja o ponto de partida e afirma: 
intervir no mundo. Quando se trata da Educação Física escolar, por situarse ela numa instância educativa formal, necessariamente se está tratando de um projeto politico-pedagógico - ideia esta amplamente presente na pedagogia.

Para Betti, então, a EF deve se apropriar criticamente da cultura corporal do movimento na busca pela construção dos objetos específicos da área que, por sua vez, necessitam de teorias que deem conta das relações dialéticas e que possam avançar, mesmo sendo rivais. Betti (2005) (re)afirma que a EF não é uma ciência, mas uma área de conhecimento e intervenções que expressa diferentes projetos de sociedade e concepções ideológicas. Nesse sentido, a reflexão sobre a atividade epistemológica torna-se fundamental para não reproduzirmos novamente dualismos e fragmentações que já vem alimentando o debate epistemológico da EF brasileira. ${ }^{9}$

$\mathrm{Na}$ busca de também propor saídas para as fragmentações causadas pelo debate epistemológico da EF no Brasil, Velozo (2010) recorre a Antropologia. Para ele, o conhecimento advindo da ciência (natural) moderna ganhou legitimidade ao ponto de se tornar hegemônico dentro do campo da EF. Velozo (2010) afirma que a $E F$, na condição de um campo multidisciplinar, se ancora tanto nas ciências naturais como nas ciências humanas, contudo, tal fato acaba estimulando a fragmentação e a especialização dentro da área.

Nesse sentido, Velozo (2010, p. 84) considera que um dos maiores problemas é a dicotomia entre o saber acadêmico e a intervenção pedagógica concreta. $\mathrm{Na}$ tentativa de contribuir com o debate, o autor propõe um olhar antropológico, fato que colocaria em xeque o saber e a razão como construções universalmente válidas e eleva a compreensão do fato social total de Marcel Mauss e do homem na sua concepção sintética (a síntese do biológico, do psicológico, do cultural e do social). Velozo (2010, p. 91) conclui dizendo que:

As contribuições para a epistemologia da educação física com base no pensamento antropológico permitem contrapor a visão naturalizada de ciência existente na área. A não separação entre realidade e representação e a consequente discussão da ciência como construção cultural evidenciam que a noção de cientificidade passa por uma construção que é sempre simbólica e local, e não natural e universal como se poderia imaginar.

Já Almeida e Vaz (2010) reconhecem que, na atualidade, dois eixos vêm norteando o debate epistemológico na EF brasileira, quais sejam: 1) os giros epistemológicos e, 2) a presença das teorias pós-modernas. Os autores defendem a virada linguística como alternativa de reconstrução do panorama crítico da área. Segundo Almeida e Vaz (2010), os estudiosos da área que lançam mão dos argumentos advindos do realismo ontológico acreditam que os giros linguísticos não dão conta do real. Para Almeida e Vaz, tal defesa desconsidera a atividade epistemológica da área, uma vez que determina quais são as contribuições realistas e as irracionalistas. Também inserido no debate a respeito dos giros epistemológicos, Fensterseifer (2009, p. 244) acredita que a hermenêutica filosófica pode ser um caminho interessante para pensar a linguagem. Para ele, 
[...] não é possível a atividade epistemológica sem o recurso da linguagem, uma vez que, concordando com Berticelli (2004, p. 89), "a experiência do mundo se traduz como linguagem. Não há outra tradução possível da experiência do mundo que não seja a linguagem". Nas palavras de Gadamer, "a peculiar objetividade do mundo decorre da relação da linguagem com ele" (apud BERTICELLI, 2004, p. 88, nota 4, grifos do autor).

Para Fensterseifer a atividade epistemológica baseada na linguagem não procura desvelar as verdades das coisas, mas sim, versar a respeito dos discursos sobre as coisas. O autor reconhece que o debate epistemológico pós-1980 no campo da EF polarizou-se entre: 1) o objetivismo científico das ciências naturais; 2) as ciências humanas e o objetivismo científico que inclui a historicidade das categorias e 3) a fenomenologia que desloca o debate para a subjetividade. Contudo, para Fensterseifer, a atividade epistemológica pautada na linguagem hermenêutica entende que os fenômenos não podem apenas serem compreendidos a partir das estruturas lógicas e devem, sobretudo, considerar a argumentação como algo que fundamenta a realidade e que, por meio da linguagem, possibilita a ressignificação dos saberes científicos dentro do campo.

A partir da análise destes textos mapeados, pode-se afirmar que o debate epistemológico do campo da EF brasileira, na primeira década do século XXI, continuou sendo travado no âmbito dos giros epistemológicos. Contudo, nota-se, também, que o debate se situou na esfera das: 1) discussões a respeito do dualismo entre as ciências naturais e as ciências humanas e; 2) específico à presença das ciências humanas na EF, considerando um dualismo particular entre as teorias "críticas" e as teorias "pós-modernas".

Nesse sentido, me parece que quando os autores lançam mão das análises antropológicas, hermenêuticas e da filosofia da ciência eles continuam interessados em disputar o campo na medida em que se preocupam em propor novas chaves de leituras do mundo (e da EF brasileira). Sem dúvida, esses novos discursos vieram acompanhados de críticas que alavancaram o debate na segunda década do século $\mathrm{XXI}$.

\subsection{EDUCAÇÃO FÍSICA E CIÊNCIA: DE 2011 ATÉ 2019}

Nos últimos anos, o campo da EF parece orientar suas discussões epistemológicas a partir de dois movimentos. No primeiro, há o aprofundamento do debate que envolve as teorias críticas diante das teorias "pós-modernas". Já o segundo têm se construído no sentido de pensar os limites e continuidades das teorias de pensadores específicos dentro do campo da EF. Nesse bojo, parece haver um deslocamento das preocupações teóricas estruturais, para uma análise voltada aos atores e seus contextos de ação.

O primeiro movimento diz respeito ao aprofundamento da polarização do debate entre aqueles que compactuam com os giros (linguísticos, hermenêutico e pragmático) numa nova forma de realizar a atividade epistemológica da área e aqueles que acreditam que essa atividade deve ser realizada a partir de um resgate da ontologia realista. No seio deste debate situam-se os textos de Motta de Souza (2011), Almeida, Bracht e Vaz $(2012,2015)$ e Rezer, Nascimento e Fensterseifer 
(2011). Percebemos, assim, que a discussão assistida na área é em relação à pertinência ou não destas classificações epistemológicas e dos rótulos que elas podem desencadear nas análises da produção científica.

No centro deste debate, Almeida, Brachte Vaz (2012) analisam as duas principais classificações epistemológicas mais utilizadas na EF: 1) a que considera a produção do conhecimento organizada em três matrizes teóricas e, 2) a que opõe o moderno e o pós-moderno no debate da área. Considerando estas classificações, os autores chegam à conclusão que há limites e insuficiências dentro delas, haja vista que estas são insuficientes para caracterizar a complexidade, as nuanças e a diversidade teórica e política presente no atual debate da área. Em razão disso, os autores acreditam que estas classificações podem desabonar rótulos na análise da produção do conhecimento da área, uma vez que oferecem análises frágeis e reducionistas das perspectivas enquadradas em determinados rótulos. Assim, ao invés de qualificar o debate e fazê-lo avançar, estas classificações acabam produzindo novos mal-entendidos e avaliações frágeis das perspectivas que nelas são enquadradas.

Motta de Souza (2011), apesar de realizar o mesmo diagnóstico que os autores supracitados, acredita que a perspectiva critico-dialética ainda é a melhor alternativa para criticar os limites e possibilidades do fazer científico no seio da sociedade capitalista. Para a autora, o olhar ancorado nas perspectivas pós-modernas desconsideram a realidade e contribuem para mercantilizar o fazer científico. Em síntese, Almeida, Bracht e Vaz (2015) defendem o pluralismo teórico e político presente na pedagogia crítica da área da EF, uma vez que estes autores acreditam que a perspectiva crítica da área tem sido marcada por esta pluralidade (teórica e política). Com isso, pretendem reconstruir a tarefa da crítica na EF, defendendo que o "pós-modernismo" pode ser também lido como uma (re)escrita ou uma radicalização da modernidade e não o seu abandono.

Ao discutirem sobre as "formas de ser" da EF na contemporaneidade, Rezer, Nascimento e Fensterseifer (2011) também acreditam na pluralidade teórica e política da atividade epistemológica, contudo, salientam que ao mesmo tempo em que presenciamos uma pluralidade teórica, também enfrentamos um "acastelamento epistemológico" que polariza pensamentos uniformes dentro de grupos de pesquisa, fato que contribui para enfraquecer a capacidade argumentativa dos pesquisadores e eliminar a presença da atividade epistemológica autônoma e reflexiva. Nesse debate, Almeida, Bracht e Vaz (2012) alertam para os cuidados com os usos e abusos de determinados autores uma vez que, tanto os usos superficiais como os usos enviesados, podem enquadrar certos pensadores, dificultando o entendimento sobre a (não) necessidade de inseri-los e utilizá-los no campo da EF.

Esse debate parece estar acompanhando um segundo movimento que visa entender os diferentes níveis de contribuição, a partir das capacidades individuais, que os mais diversos autores têm de ordenar a totalidade da área da EF. Os textos de Vaz (2019), Bungenstab (2018), Souza (2019b), Nóbrega (2014), Guidetti (2013) e Seron et al. (2011) discutem diferentes autores dentro do campo da EF. Seron et al. (2011, p. 82) procuraram entender como a teoria de Vygotsky tem sido usada na produção da EF brasileira. 
Quanto aos conceitos vigotskianos [...] 66,1\% dos conceitos se referiam a questões da linguagem, e sua relação com a leitura e a escrita, as funções psicológicas superiores, o meio social, os conhecimentos espontâneos e científicos, a consciência, a educação inclusiva e aspectos ligados à escola e ao professor. Dentre esses conceitos, foram encontrados alguns equívocos de interpretação.

Seron, Barbosa-Rinaldi e Tuleski (2011) ainda atentam para a preocupação iminente que o campo da EF deve ter no trato minucioso com as teorias de Vygotsky, sobretudo, na consideração de que o uso fiel do autor pode propiciar à EF transformações de cunho epistemológicos. Bungenstab (2018) realizou um levantamento bibliográfico com o intuito de mapear a presença do sociólogo Anthony Giddens na produção científica do campo da EF. Bungenstab (2018, p. 785) conclui dizendo que a área realiza dois tipos de leituras a partir da obra de Giddens: uma leitura geral e uma leitura específica (que procura pensar o corpo no que tange à autoidentidade e as discussões a respeito do papel do esporte nas políticas públicas).

Já Souza (2019b) faz uso dos escritos de Giddens e Ulrich Beck na tarefa de realizar um "manifesto" reflexivo para pensar a estruturação teórica da EF. Para tal, acredita na ideia da construção de "biografias do movimento": algo possível de ser realizado a partir da reflexividade do se-movimentar numa perspectiva não restrita e que contemple várias abordagens da EF. Recentemente, Marani, Lara e Souza (2019) deram prosseguimento ao debate iniciado por Souza (2019b), levando em consideração as ideias de Giddens sobre auto-identidade e reflexividade. Os autores concluíram que:

[...] o "eu" não é fixo e, por isso, o corpo também não o é; há uma relação direta com a narrativa biográfica a ser sustentada. Nesse contexto, as relações do "eu" com o corpo por meio das práticas corporais passam a ser entendidas a partir de um projeto de "chances arriscadas" (BECK, 2011) no qual os indivíduos buscam a projeção de suas autoidentidades, construídas e mantidas por meio do constante monitoramento da superfície projetada socialmente - o corpo.

Ghidetti (2013), por sua vez, analisa a produção de Valter Bracht diante do debate epistemológico da EF reconhecendo a importância deste autor no seio das discussões a respeito da cientificização da EF no fim do século XX. Guidetti (2013) ressalta que Bracht, no século XXI, tem se interessado mais em discutir a respeito dos conhecimentos tratados pela EF. Para tal, desloca seu pensamento tendo como base a virada linguística. De tal modo, Bracht acompanhou a transformação do debate epistemológico da EF, tendo participado primeiro das discussões a respeito da cientificização da área e depois se inserido, também, no debate sobre os giros epistemológicos e as teorias pós-modernas.

Já Vaz (2019, p. 10), procurou compreender e analisar o alcance da abordagem marxista na EF brasileira, mais precisamente situando a temática do corpo ${ }^{10} \mathrm{em}$ Marx e Gramsci a partir do Movimento Renovador da EF:

O ideário de cada um deles aparece na Educação Física brasileira contemporânea, quando é o caso, muito mais como aporte analítico e crítico da sociedade e da educação. Mas seria o caso de considerar o

10 Também discutindo o corpo, Nóbrega (2014) faz uso das análises que Merleau-Ponty realizou a respeito da noção de natureza deslocando o debate da fenomenologia para uma ontologia do ser selvagem. 
legado de ambos e observar até que ponto o que escreveram sobre o tema impacta outros aspectos das respectivas Obras.

Para Vaz (2019), o Movimento Renovador da EF, apesar de ter se constituído como uma importante força intelectual da EF brasileira, não se dedicou de maneira efetiva nas questões teóricas envolvendo o corpo, sobretudo, tendo Marx como referência. Nesse sentido, Vaz (2019) sugere que façamos algumas releituras da obra de Marx no intuito de refletir sobre as contradições sociais sintetizadas pelo corpo (considerando-o como expressão do gênero humano) e as (im)possibilidades do ensino das práticas corporais na tarefa de superação das desigualdades contemporâneas.

Após este mapeamento, percebe-se que o debate epistemológico atual da EF brasileira continua pautado pela discussão dos giros e da presença dos "pósmodernos", contudo, o mapeamento sinaliza outro caminho que a produção do campo da EF parece estar trilhando: não se preocupar em discutir, no âmbito estrutural, as diferentes concepções de ciência e de verdade, mas sim, direcionar-se na tentativa de compreender, analisar e refletir quais são os limites e possibilidades que os mais diversos autores trazem para a EF.

\section{CONCLUSÕES}

Esse texto procurou apresentar e analisar, em termos de artigos científicos, a produção desenvolvida pelo campo da EF no que diz respeito as (re)configurações do debate epistemológico da área. Notou-se que, no século $\mathrm{XXI}$, o debate epistemológico aprofundou questões já salientadas nos textos de Almeida e Vaz (2010) e Fensterseifer (2009), quais sejam: a preocupação com as matrizes teóricas; os giros epistemológicos e a presença das teorias pós-modernas.

Contudo, nos últimos anos, o campo da EF parece estar se afastando do que Rezer, Nascimento e Fensterseifer (2011) chamaram de "acastelamento epistemológico", uma vez que começa a analisar epistemologicamente a contribuição de diversos autores sem enquadrá-los em uma perspectiva específica. Tal fato é importante, sobretudo, porque aguça os pesquisadores a desenvolverem suas autonomias intelectuais e entenderem que há limites e possibilidades em diversas teorias/autores. Além do mais, a análise da produção científica, quando realizada epistemologicamente faz a EF olhar para si na busca de compreender: 1) como viemos parar neste debate; 2) para qual lugar estamos direcionando o debate epistemológico da área; e, 3) até que ponto este debate traduz epistemologicamente o que é a área em sua diversidade biossocioantropológica;

O que parece é que se torna fundamental continuar defendendo a pluralidade de teorias e ideias na área, sobretudo, porque ela permite que o debate se mantenha no nível das lutas travadas entre as ciências e as matrizes teóricas, mas também oportuniza que adentremos no âmbito do debate envolvendo autores específicos e suas leituras. Acredito que só dessa forma o campo da EF conseguirá (re)descrever sua própria trajetória enquanto área do conhecimento que pensa e se movimenta. 


\section{REFERÊNCIAS}

ALMEIDA, Felipe Quintão; VAZ, Alexandre Fernandes. Do giro linguístico ao giro ontológico na atividade epistemológica em Educação Física. Movimento, v. 16, n. 3, p. 11- 28, jul./set. 2010.

ALMEIDA, Felipe Quintão; BRACHT, Valter; VAZ, Alexandre Fernandes. Classificações epistemológicas na Educação Física: redescrições... Movimento, v. 18, n. 4, p. 241-263, out./dez. 2012.

ALMEIDA, Felipe Quintão; BRACHT, Valter; VAZ, Alexandre Fernandes. Educação Física, pedagogia crítica e ideologia: gênese e interpretações. Movimento, v. 21, n. 2, p. 317-331, abr./jun. 2015.

BETTI, Mauro. Educação física como prática científica e prática pedagógica: reflexões à luz da filosofia da ciência. Revista Brasileira de Educação Física e Esporte, v. 19, n.3, p. 183-197, 2005.

BUNGENSTAB, Gabriel Carvalho. A presença de Anthony Giddens na produção científica da educação física brasileira: entre a reflexão e o deslize. Movimento, v. 24, n. 3, p. 777-788, jul./set. 2018.

FENSTERSEIFER, Paulo Evaldo. Crise da Racionalidade Moderna e a Educação Física. Revista Brasileira Ciências do Esporte, v 2, n.1, p. 35-36, 2000.

FENSTERSEIFER, Paulo Evaldo. Epistemologia e Prática pedagógica. Revista Brasileira Ciência do Esporte, v. 30, n. 3, p. 203-214, maio 2009.

GHIDETTI, Filipe Ferreira. Notas sobre o teorizar em educação física: um olhar sobre a contribuição de Valter Bracht ao debate epistemológico. Movimento, v. 19, n. 3, p. 257-274, jul./set. 2013.

GOMES, Isabela Sena; CAMINHA, Iraquitan. Guia para estudos de revisão sistemática: uma opção metodológica para as Ciências do Movimento Humano. Movimento, v. 20, n. 1, p. 395-411, jan./mar. 2014.

GOMES, William B. Gnosiologia versus epistemologia: distinção entre os fundamentos psicológicos para o conhecimento individual e os fundamentos filosóficos para o conhecimento universal. Temas em Psicologia, v. 17, n. 1, p. 37-46, 2009.

KOKUBUN, Eduardo. Negação do caráter filosófico-científico da educação física: reflexões a partir da biologia do exercício. In: FERREIRA NETO, Amarílio; GOELLNER, Silvana; V.; BRACHT, Valter. (org.). As Ciências do Esporte no Brasil. Campinas: Autores Associados, 1995.p. 53-71.

LIMA, Homero Luís Alves de. Pensamento Epistemológico da Educação Física brasileira: das controvérsias acerca do estatuto científico. Dissertação - (Mestrado em Educação) - Universidade Federal de Pernambuco, Recife, 1999.

MARANI, Vitor Hugo; LARA, Larissa Michelle; SOUZA, Juliano de. O agenciamento do corpo na modernidade reflexiva: notas e excertos a partir de Anthony Giddens. Movimento, v. 25, p. e25046, jan./dez. 2019.

MOTTA DE SOUZA, Julia Paula. Epistemologia da educação física: análise da produção científica do programa de pós-graduação da faculdade de educação física da Unicamp (1991-2008). Motrivivência, n. 36, p. 247-267, jan. 2011. 
NÓBREGA, Terezinha Petrúcia da. Corpo e natureza em Merleau-Ponty. Movimento, v. 20, n. 3, p. 1175-1196, jul./set. 2014.

PETERS, Michael. Pós-estruturalismo e filosofia da diferença. Belo Horizonte: Autêntica, 2000.

REZER, Ricardo; NASCIMENTO, Juarez; FENSTERSEIFER, Paulo Evaldo. Um diálogo com diferentes "formas-de-ser" da educação física contemporânea - duas teses (não) conclusivas... Pensar a Prática, v. 14, n. 2, p.1-14, set. 2011.

SERON, Taiza Daniela; BARBOSA-RINALDI, leda Parra; TULESKI, Silvana Calvo. Apropriação dos conceitos de Lev Semenovitch Vygotsky no âmbito das pesquisas em educação física. Movimento, v. 17, n. 2, p. 75-91, abr./jun. 2011.

SÉRGIO, Manuel. Educação Física ou Ciência da Motricidade Humana. 2. ed. São Paulo: Papirus, 1991.

SÉRGIO, Manuel. Para uma epistemologia da Motricidade Humana - prolegômenos a uma nova ciência do homem. 2.ed. Lisboa: Compendium, 1994.

SONI, Gunjan; KODALI, Rambabu. A critical analysis of supply chain management content in empirical research, Business Process Management Journal, v. 17, n. 2, p. 238-266, 2011.

SOUZA, Juliano de. Digressões acerca da ciência aplicada do movimento humano (ou sobre como podem prosperar revoluções simbólicas na área de Educação Física?). Revista Brasileira de Ciência e Movimento, v. 27, n. 4, p. 43-63, 2019a.

SOUZA, Juliano de. Educação física reflexiva - problemas, hipóteses e programa de pesquisa. Movimento, v. 25, p. e25002, jan./dez. 2019b.

VAZ, Alexandre Fernandez. Certa herança marxista no recente debate da educação física no Brasil. Movimento, v. 25, p. e25069, jan./dez. 2019.

VELOZO, E. L. Educação física, ciência e cultura. Revista Brasileira de Ciências do Esporte, v. 31, n. 3, p. 79-93, 2010. 